\title{
Individual Differences in Non-Regulatory Ingestive Behavior and Catecholamine Systems
}

\author{
(iLYY MITIIEMAN' and ELLIOT S. VALENSTEIN \\ Psychology Department and Neuroscience Laboratory Building, The Liniversity of Michigan. Ann Arbor. MI 48104-1087 (1:.S. A. I
} (Accepted February 12th, 1985)

Key words: amphetamine - schedule-induced polydipsia - electrical stimulation - lateral hypothalamus - catecholamine dopaminc - individual differences - eating and drinking

\begin{abstract}
Animals that cat and/or drink in response to electrical stimulation of the lateral hypothalamus (ESLH-pos) are more responsive to both schedule-induced polydipsia (SIP) tests and a series of amphetamine (AMPH) injections than animals that do not exhibit these behaviors (ESLH-neg). Moreover, prior exposure to the behaviorally activating SIP experience, or to AMPH, permanently transformed the ESLH-neg animals into animals that reliably ate or drank during ESLH. Prior treatment with AMPH also increases the water consumed during subsequent SIP tests. Thus, initial of induced differences in sensitivity to activating experiences can determine behavioral propensities.
\end{abstract}

\section{INTRODUCIION}

Evidence that eating and drinking can be evoked in satiated animals by such diverse conditions as electrical stimulation of the lateral hypothalamus, schedule-induced polydipsia, tail-pinch, social facilitation. and numerous non-specific stressors suggests that ingestive behavior can be influenced by factors other than nutritional needs $3.4,7.11 .13 .14 .17 .23,28,310.32 .36 .37 .38 .42$. We propose calling such eating and drinking 'nonregulatory ingestive behavior' to emphasize that different mechanisms may underlie this behavior and the eating and drinking motivated by nutritional and fluid imbalances 15.33 . What seems to be common to the diverse experimental conditions capable of evoking 'non-regulatory ingestive behavior' is that they all produce behavioral activation ${ }^{14,23.27}$. It has also been suggested that some intermediate level of stress is often involved $12,2,0,35,39$.

Of particular relevance to the present investigation is the demonstration that animals differ in their predisposition to engage in 'non-regulatory ingestive behavior ${ }^{\circ}, 18,19,32,37,40$. Recently, the present authors found that these individual differences may be consistent across experimental conditions as animals that ate and drank in response to electrical stimulation of the lateral hypothalamus (ESLH) exhibited significantly more 'displacement drinking' when tested in a schedule-induced polydipsia (SIP) paradigm ${ }^{14}$. SIP has been considered an example of 'displacement drinking' or 'psychogenic polydipsia' that is often evoked when a hungry animal is frustrated by giving it a small amount of food and then thwarting further eating for a period of time. Although this interpretation has been questioned ${ }^{12}$, it has been frequently observed that animals undergoing SIP tests typically become very active and often very irritable ${ }^{14}$.

The purpose of the present investigation was to explore the basis of the individual differences in 'nonregulatory ingestive behavior. As catecholamines are generally recognized to be involved in behavioral activation 1.2.9.111.10.31 and dopamine (DA), in particular, has been implicated in ESLH- and SIP-induced ingestive behavior $20.21 .24 .25 .24 .3 \%$. we investigated whether some property of DA systems might underlic the differences in 'non-regulatory ingestive be-

Correspondence: E.S. Valenstein. Neuroscience Laboratory Building. The Liniversity of Michigan. 110.3 E. Huron Street. Ann Arbor. MI 48104-1687. U.S.A. 
havior. Fvidence of a difference in catecholamine systems related to the predisposition to exhibit nonregulatory ingestive behavior' has been found. It has also proven possible to increase the predisposition to exhibit 'non-regulatory ingestive behavior' by exposing animals to environmental or biochemical stimulation known to increase the responsiveness of catecholamine systems ${ }^{+1}$.

Specifically. it is now reported that: (1) rats that display 'non-regulatory ingestive behavior' have a significantly greater response to amphetamine than animals that do not exhibit this behavior: (2) following a regimen of amphetamine, animals display significantly more 'non-regulatory' drinking': and (3) animals that did not eat drink in response to FSLH start to display this behavior after they have been exposed to either a regimen of amphetamine or schedule-induced polydipsia testing.

\section{MATHRIALS A.VD METHODS}

\section{Subjects and surgical procedure}

The subjects were mature $(366-480 \mathrm{~g})$. male Long-Fvans hooded rats (Simonsen. Gilroy. CA) that were housed individually in wire-hanging cages. The vivarium was temperature regulated and lights were maintained on a 12-12 h dark-light cycle. Each rat was anesthetized with Equithesin (Jensen-Salsbery. Kansas (ity. MO) and twisted bipolar stainless steel electrodes (Plastic Products. Roanoke, VA. No. MS 3013:1.25 mm diameter) were bilaterally implanted into the lateral hypothalamus (coordinates: $3.5 \mathrm{~mm}$ posterior to bregma. $1.5 \mathrm{~mm}$ lateral to the sigittal suture. and $8 .+\mathrm{mm}$ below the surface of the skull surface. which was level between bregmal and lambda). The electrodes were fixed to the skull by stainless steel screws and cranioplastic acrylic.

\section{ESL.H-lesting procedure}

Onc week following surgery, animals were tested in a Plexiglas chamber for the behavior evoked by F.SI.H. Stimulation consisted of $20 \mathrm{~s}$ trains of $60 \mathrm{~Hz}$ sine waves alternating with $15 \mathrm{~s}$ intertrial intervals. During testing. $75 \mathrm{mg}$ food pellets (P.J. Noyes) were distributed evenly over the floor, and a standard watter bottle with a metal drinking tube was attached to one wall. Stimulation intensity was increased in $1 \mu \mathrm{A}$ steps until the animal either ate or drank, or until the stimulation produced excessive agitation or 'forced" motor responses that precluded eating or drinking.

Animals that ate or drank were given additional stimulation at a current intensity just above threshold until they ate or drank on 5 consecutive stimulations. The number of food pellets eaten. the duration of drinking, and the current intensity threshold were recorded. Animals that did not eat or drink were given an additional 2-4 tests separated by $48-72 \mathrm{~h}$. After screening with the right hypothalamic electrode. animals were tested for their response to stimulation at the left electrode. Rats that reliably displayed eating. drinking or both behaviors during stimulation at either electrode, were designated ISSI.H-pos; those that did not eat or drink were classified I:SI.H-neg

\section{EXPFRIMFNI 1}

The effect of prior exposure to schedule-induced polydipsia (SIP) on sensitivity to A.MPH. Comparison of ESI.H-pos and ESI.H-neg rats.

Following testing for ESLH-elicited ingestive behavior both ESLH-pos $(n=28)$ and ESI.H-neg $(\mathrm{n}=20)$ rats were divided into) two weight matched groups. All rats were reduced to $85 \%$ of their free feeding weight. The two experimental groups were given 10 daily 30 min SIP tests in a Plexiglas cage equipped with a food dispenser and two water filled Richter tubes located $5 \mathrm{~cm}$ on either side of the dispenser. During the SIP test. a $75 \mathrm{mg}$ food pellet was delivered every 60 s. After each test. the lotal amount of water consumed was recorded and animals were weighed and given sufficient food in their home cages to assure that they would be close to $8.5 \%$ of their body weight when tested 24 h later. The two control groups were not exposed to the SIP procedure, but received daily handling similar to the experimental animals including placement in the SIP test chambers and food deprivation.

After completion of the 111 SIP tests, all animals were given free access to food for 1 month in their home cages. The experimental (ESIJH-pos-SIP. $\mathrm{n}=11$ : ESLH-neg-SIP. $\mathrm{n}=1(1)$ and control animals (ESLH-pos-C()N. $n=17$ : FSL.H-neg-CON, $n=10$ ) were then tested for amphetamine (A.MPH) stereotypy following injection of $3.25 \mathrm{mg} \mathrm{kg}$ (i.p.) D-amphetamine sulfate dissolved in (1.9\%' saline. This dose of AMPll was used hecause it was shown in pilot 
studies to produce individual differences in stereotyped behavior. Beginning 10 min after the A.MPH injection each animal's behavior was videotaped for $1 \mathrm{~min}$. every $10 \mathrm{~min}$, for a total of $2 \mathrm{~h}$ (i.c. $12.1 \mathrm{~min}$ samples of behavior). An observer. unaware of the animals history. used the videotape records io rate stereorypy on al scale modified from MacLennan and Mater' in which: 1 = intermittent activity: $2=$ =continuous activity: $3=$ intermittent stereotypy (stereotyped sniffing. rearing or repetitive head movements): $4=$ continuous stereotypy over a wide area: 5 - continuous stereotypy in a restricted areal $0=$ pronounced continuous stereotypy in a restricted areal $7=$ intermittent stereotyped biting and licking directed at the walls and floor: and $s=$ continuous stereotyped biting and licking in a restricted arcia. In addition, a locomotor activity score was obtained by counting the number of quarter $\left(90^{\circ}\right)$ turns in each 1 min segment.

\section{RESLLIS}

As is evident in Fig. 1 (top), following the injection of $\mathrm{AMPH}$. the stereotypy scores of the ESLH-pos animals exposed to SIP were significantly higher than the scores of the ESLH-neg-SIP animals (profile analysis: $F=4.657$, df $=1.19 . P<0.044)$ and also significantly higher than all 3 other groups combined (profile analysis: $F=5.87$. df $=3.44 . P<0.002)$. While $91 \%$ of the ESLH-pos-SIP rats showed stereotyped behavior in a restricted area of the test cage. a more intense response to AMPH than locomotion. $60 \%$ of the ESL.H-neg-SIP animals and only 15\%; of the animals in either control group exhibited this behavior at all. This difference was statistically significant $\left(\chi^{2}=20.37\right.$. df $=2 . P<0 .(11)$.

Analysis of the locomotor activity scores shown in Fig. 1 (bottom) indicated that ESLH-pos rats that had undergone SIP testing were significantly less active than all other rats (profile analysis: $F=4.16$. df $=1.33 P<0.05)$. Rats in this group exhibited an initial increase in locomotion. but within $10 \mathrm{~min}$ after the amphetamine injection. stercotypy increased and locomotion declined sharply and remained low throughout the 2 h test (Fig. 1. bottom). This wats true only of the ESI.H-pos-SIP animals, as the rats in the other 3 groups typically exhibited an increase in locomotor activity following $\triangle \mathrm{MPH}$ administration
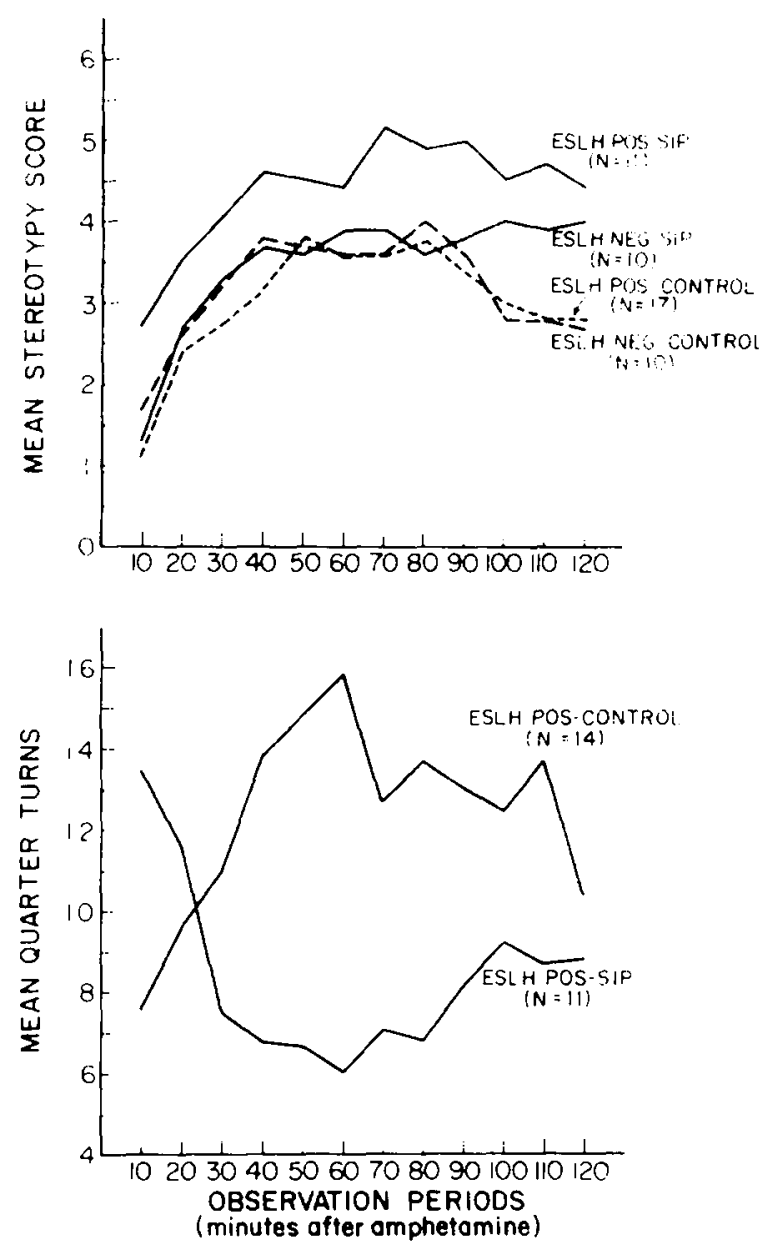

Fig. 1. Top: the average stercotypy score tor each 1 min observation period during the $2 \mathrm{~h}$ following amphetaminc injections. Bottom: the average number of quarter turns in each $1 \mathrm{~min}$ ob. servation period.

that was sustained throughout the $2 \mathrm{~h}$ test.

\section{EXPERIMENI 2}

The effect of AMPH sensitization on ingestive behavior elicited by SIP and ESL.H.

Naive rats were implanted with lateral hypothalamic electrodes and tested for ESLH-induced eating and drinking as described in Lixpt. 1. Only the ESL.H. neg rats were used and these were divided into the following 4 groups. Group 1 ( AMPH-SIP; $n=7$ ) was given twice daily i.p. injections ( $8 \mathrm{~h}$ apart) of $5 \mathrm{mg} / \mathrm{kg}$ AMPH in their home cages for 5 days. This regimen has been shown to increase the responsivity of catecholamine systems and to elevate striatal dopamine 
release 22.2 . Group 2 (saline-SIP; $n=6$ ) were given twice daily injections of $0.9 \%$ saline on the same schedule. One week following the last injection. when Groups 1 and 2 were at comparable weight the rats were food deprived to $85 \%$ of their free feeding weight and given 10 SIP tests, as described in Expt. 1. Group 3 (AMPH: $n=7$ ) and Group $4($ saline: $n=5$ ) animals were injected with AMPH or saline. respectively. as described above. but were not given SIP tests. Rats in Groups 2 and 4 that received saline injections were partially food deprived during the injection period to control for the weight loss of the AMPH rats (mean weight loss: $A M P H-9.29$ : saline -9.33 ). Six weeks following completion of the injection schedule all animals were retested with ESLH. At the time of the ESLH testing. animals had been on ad lihitum feeding for at least 3 weeks.

\section{RESLIITS}

The results clearly show that pretreatment with $A M P H$ increased the amount of schedule-induced drinking displayed (Fig. 3). During the SIP testing. ESL.H-neg rats that were sensitized with AMPH displayed significantly more drinking than saline-injected animals $($ ANOVA: $F=7.33, \mathrm{df}=1.11, P<$ 0.(12). As previously reported, untreated ESI.H-neg animals drank very little water during SIP tests ${ }^{1 "}$. As is evident in Fig. 2. the significant increase in amount of water consumption of the AMPH animals over the 10) test days was particularly striking. This increase over days was statistically significant (ANOVA: $F=$ 5.502. . If $=9.99 . P<0.0(01)$. The ESLH-neg rats that received saline injection did not increase their sched-

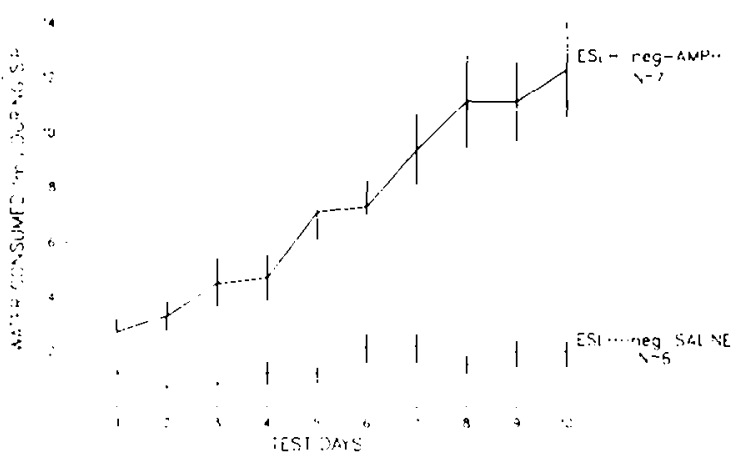

Fig. 2. The average ( \pm S.F.M) amount of water consumed in each SIP test of rats pretreated with amphetamine or saline.

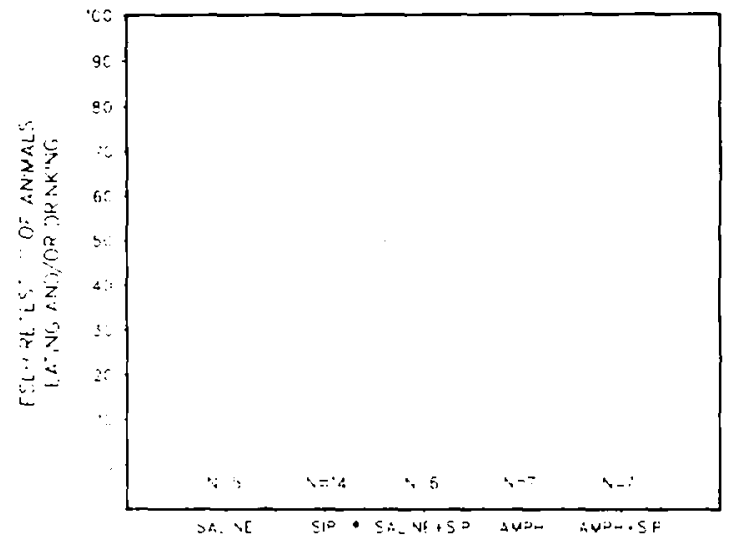

Fig. 3. The percentage of originatly F.SL H-neg rats that ate or drank when retested for ESL.H-elicited behavior after different experiences (see text). (" from Mittleman and Valenstein. 19841 On retest. significantly fewer ESI.H-neg rats that recieved saline pretratment drank than any other group $(\%$ ranged from +.1 to $6.1, \mathrm{df}=1, P<0.115)$.

ule-induced drinking during the SIP tests. In addition. whereas $100 \%$ of the AMPH animals were drinking by test day 8 . only $57 \%$ of the saline animals drank even on day 10 and the amount consumed was relatively low:

Exposure to SIP or AMPH significantly changed the response of many animals when they were retested for ESLH-elicited ingestive behavior (Fig. 3). Following AMPH treatment. 57\%; of the previously ESI.H-neg rats in the non-SIP group ate and or drank during ESLH in contrast to (0); of the saline-non-SIP group. After the SIP experience. $50 \%$ of the salineinjected rats became ESL.H-pos, while 71\%; of the rats that were given both $A M P H$ injections and the SIP tests exhibited FSLH-elicited eating and drinking when retested. The animals that became FSL.Hpos ate and drank as reliably as the animals initially classified as positive, and they consumed as much. The current threshold for evoking this behavior was also comparable. As the animals continued to eat and drink in response to ESLH when tested repeatedy during a one month period. the change appeared to be permanent.

\section{DISCUSSION}

The results lend considerable support to the hypothesis that predisposition to display 'non-regulatory eating and drinking is related to some property of 
catecholamine systems. Expt. I demonstrated that the ESLH-pos animals exhibited significantly more stereotypy in response to amphetamme alter exporsure to a series of behaviorally actirating sIP lests. To he noted. however, is the finding that ISSI.H-pos and ESLH-neg animals did not differ in their response to AMPH unless the had been exposed to the SIP testing schedule (Fig. 1). Apparently. the ditferences between the ESLH-pos and -neg anmals is not erident in their response to AMPH until the neural systems stimulated by this drug have heen sensttized by the SIP experience. This 'ensitization" appears to be long-lasting as it was evident when the animals were tested one month after the SIP tests As the more intense stereotyped responses to AMPH are thought to be dependent on DA mechanisms"... these results suggest that differences in predisposi-

\section{RFFERENCES}

1 Antelman. S.M. and (hiodo. L.A.. Amphetamine as a stressor. In I. (reese (Ed). Simulants. Neturochemical. Behavioral, and clinical Peripectives, Raven. Vew York. 1983. pp. $269-290$

2 Antelman, S. M and Chiodo, L. A. Stress: its effect on interactions among biogenic amines and role in the induction and treatment of discase. In I.. L. Iversen. S. D. Jversen and S.H. Snyder (Eds.). Handbook of Psychopharmacolog!. Plenum, New York, 1984. pp. 279-311.

. Antelman. S.F.. Rowland. N.F. and Fisher. A.E... Stimulation-bound ingestive behavior: a view from the tail. Physiol. Behar., 17 (1976) 74.3-748.

4 Antelman, S.M. and Szechtman. H. Tail-pinch induces cating in sated rats which appears to depend on nigrostriatal dopatmine. Science. 189 (1975) 7.31 .733

S Bachus, S.I. and Valenstein. E.S. Individual behavioral responses to hypothalamic stimulation persist despite destruction of tissue surrounding electrode tip. Phstol. Bi' has. . 23(1979) +21-126.

6 Brett. 1.P. and Levine. S. Schedule-induced polydipsia suppresses pituitary-adrenal activity in rats. $J(P /)$. S ( 1479$)$ $9+6-956$.

7 (antor. M.B. Bad habits: modeis of induced ingestun in satiated rats and people. In S.A. Miller (Fd.). Behavier and Vutrion, Fratnklin Inst. Press. Philadelphial. 1981, Pp. 314.

8 (reese. I. and Jversen, S.I). The pharmacological and anatomical substrates of amphetamine response in the rat. Brain Researk $8.3(1975) 242-246$.

4 Curzon. (j.. Hutson, P.It and Knot. P.J. Voltammetry in vivo: effect of stressful manipulations and drugs on the caudate nucleus of the rat. Br. I. Pharmasol., of (1979) $127 \mathrm{P}-128 \mathrm{P}$

I1 Dunn. A.J. and Kramarey. N.R.. Veurochemical responses in stress: relationships between the hypothalamicpitultary-adrenal atnd catecholamine systems. In 1. I. . Ner.
Ion to eat and drink in response 10 LSt H It related fo some propert! of neuronat circusts that atithe this transmitter

1.xpt. 2 demonstrated that the majorits al H:SL.h. neg animals. that are sensitied by at regimen of ansphetamine injections, become l:SL.H-pes. Such animals also tend to drink atypically high amounts of wa ter during SIP tests. The percentage of lest.ht-neg that became HSL.H-pos Was greatest in anmals that underwent both the amphetamine-sensitization and the SIP testing. These results provide a strihing ex ample of how repeated exposure to either environmental or pharmacological experiences that modity catecholamine systems mat influence subsequent be havior. We helieve the present results have applicability to behaviors other than non-regulatory ingesive behaviors:

sen, S.D. Luersen and S.H. Snyder. (Eds.). Handboek of Pswchopharmacologg: Plenum. New York lost. pp $4.5-514$

i Falk, J.1... Production of polydupsia in normal rats by an $\mathrm{m}$ termittent forod schedule. Science. $133(1961) 195-196$.

1.2 Falk. J.L... ('onditions producing psychogenic polydipsia in animals. Ann. Vew York Acad. Sit. 157 (1969) S69..593.

13 Fitk, J.L.. The nature and determinants of adjunctive he. havior. Phisiol. Behar., 6 (1971) 577-588.

It Karz. D. Animals and Man. Ponguin. Hammondworth. $1953 . \mathrm{pp} .117-118$.

15 Kissileff. H.R. Nonhomeostatic controls of drinking. In A.N. Fpstein. H.R. Kissileff and F: Stellar (F.ds.). The Veuropsychology of Thirst: Ne's Findings and thance's in concepts, V.H. Winston. Washington DC. 1473. PP. 16.3 .198

10 MacLennan. A.J. and Maier. S.F. Coping and the stres induced potentiation of stimulant stereotupy in ibe ralt. Science. $214(1983) 1091-1093$

i? Mayer. J.L and Pudel. V.F. Lxperimental studies on food-intake in obese and normal-aeight subjects. $I$. Pro. ihosom. Res. 10(1972) 305-30s

is Mitleman. ( 3 . and Valenstein. L..S. Strain differences in atting and drinking evoked by electrical stimulation of the

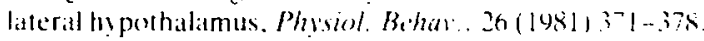

10 Nitteman. ( $i$, and Valenstein. E.S. Ingestive hehation croked by hypothalamic stimulation and schedule-induced polvedipsia are related. Science, $22+(198+1)+15-41^{\circ}$

20 Phillips, A.(i. and Fihiger. H.C. The multivariate nature of motivated behavior elicited by electrical stimulation of the lateral hypothalamus. In $\mathrm{W}$ I. Veate and $\mathrm{K}$ ledaris (Eds.). Current Sudaes of Hypothalamic Function. Iol 2. Karger. Basel. 1978, pp. 195-2115

2) Phillips. A G. and Nikaido. R.S. De Dssuption of hratt stim. ulation-induced feeding by dopatmine receptor blockade Viuture llondont). 258 (1975) $750 . .751$.

I2 Randrup. A and Munkvad, I. Stereotyped activilles pro duced hy amphetamine in several animal specien. Purho 
pharmacologia. I (1967) 30()-310).

2.3 Robbins. T.W. and Fray, P.J., Stress-induced eating: fact, fiction or misunderstanding? Appetite, $1(1980) 10.3-1.33$

24 Robhins. T.W. and Koob. G.F.. Selective disruption of displacement behaviour by lesions of the mesolimbic dopamine system. Nature (London), $28.5(1980)+109-412$.

is Robhins. T.W. . Ruherts. D). ( $S$ and Koob. (j. F.. Effects of $\mathrm{d}$-amphetamine and apomorphine upon operant behasor and schedule-induced licking in rats with 6-hydroxydopamine-induced lesions of the nucleus accumbens. J. Pharmacol. Exp. Ther. 224(1983) 6102-673.

26. Rohinsun. T.E. and Becker. J.B.. Behavioral sensitization is accompanied by an enhancement in amphetamine-stimulated dopamine release from striatal tissue in vitro. Eur. J. Pharmacol. 85(1982) $253 \cdot 254$.

27 Rebinson. T.I... Becker. J. B. and Presty. S.K. Long term facilitation of amphetamine-induced rotational behavior and stratal dopamine release produced by a single exposure to amphetamine: sex differences. Brain Research, 253 $(1982) 231-2+1$

2x Rowland. N.E. and Antelman. S.M. Stress-induced hyperphagia and obesiry in rats: a possible model for understanding human obesity. Science. 191 (1976) 310. 312 .

29 Rouland, $\mathrm{N}$. Marques, D.M. and Fisher. A.F. Comparison of the effects of brain dopamine-depleting lesions upon oral hehaviors elicited by rail pinch and electrical brain stimulation. Physiol. Behar., 24 (1980) 273-281

30 Slouchower. I. Emotional labeling and over-eating in obere and normal weight individuals. Psichosomatic Med. $38(1976) 1.31-139$.

31 Thierry. A M. Iassin. J.P. Blanc, G. and Glowinski J., Selective activation of the mesocortical DA system by stress. Vaume llondon). 26.3 (1976) 242-244.

32 Valenstein, E.S., Behavior clicited by hypothalamic stimu lation: a prepotency hypothesis. Brain Behar. Fiol. 2 $11969) 295-316$

3.3 Valconstein. F.S. Flectrical stimulation and hypothalamic function: historical perspective. In A N . Fpstein. H. R. Kissileff and E. Stellar (F.ds.). The Neuropstehology of Thirst: tew Findings and Advances in comcopts. V.II. Winston. Washington. DC. 1973.pp. 155-161.

it Valenstein, E.S. The interpretation of behavior eroted hs electrical stimulation. In $\mathrm{A}$. Wauquier and $\mathrm{I}: \mathrm{I}$. Roll (Eds.). Brain-Stimulation Reruard. North-Holland. Amsterdam, 1976. pp. 557-575

35 Valenstein. E.S. Stereotypy and semory-motor changes eroked by hypothalamic stimulation: pomsible relation as schizophrenic behavior patterns. In A. Routtenterg (E.d.). Bology of Reinforcement. Academic Press. New York. 1980. pp. 39-52

36 Valenstein. E.S. Cox, V.C. and Kakolewskı, J, W. . Modification of motivated hehavior elscited by electrical stimulation of the hypothadamus, Science $1.59(1968) 1119-1121$

37 Valenstein. E.S. Cox. V.C. and Kakolewski, J.W. A reexamination of the role of the hypothalamus in motivation. Psychol Rer.. 77(1970) 16-31.

38 Wavner, M.J., Barone. F.C. and Loullis. ( $(C$. Ihe lateral hypothalamus and adjunctive hehavior. In P.J. Morgane and J. Panksepp (Eds.). Handbook of the Hypothalamus. Vol. 3-Part B. Behavioral Studies of the Hipothalamus. Marcel Dekker Neu York. 1981, pp 107-145

39 Wallace. M.. Singer. (i. Finlat. J. and (jihson. S. The et. fect of 6-()HDA lesions of the nucleus accumbens septum on schedule-induced drinking, wheelrunning and corticosterone levels in the rat. Pharmool. Biochem. Behat., is (198.3) 129-1.36.

40 Wise, R.A. Individual differences in the effects of hypothatamic stimulation: the role of stimulation locus. Phisted. Behas., 6(1971) 564-572?

4 Yuwiler. A. Stress. In A l ajtha (Ed.), Handbook of Veurochemistrs. Vesl. o. Plenum. New York. 197i. pp. $103-171$

42 Zajonc. R.B. Social facilitation, Sctence. It9 (1965) $269-274$ 